\title{
Sequential Ground Motion Effects on the Behavior of a Base-Isolated RCC Building
}

\author{
Zhi Zheng, ${ }^{1,2}$ Xiaolan Pan, ${ }^{1,2}$ and Xu Bao ${ }^{1,2}$ \\ ${ }^{1}$ School of Civil Engineering, Harbin Institute of Technology, Harbin 150090, China \\ ${ }^{2}$ Key Lab of Structures Dynamic Behavior and Control, Harbin Institute of Technology, Ministry of Education, \\ Heilongjiang, Harbin 150090, China \\ Correspondence should be addressed to Xiaolan Pan; panxiaolan.hit@qq.com
}

Received 18 June 2017; Accepted 11 October 2017; Published 7 November 2017

Academic Editor: Roman Wendner

Copyright (C) 2017 Zhi Zheng et al. This is an open access article distributed under the Creative Commons Attribution License, which permits unrestricted use, distribution, and reproduction in any medium, provided the original work is properly cited.

\begin{abstract}
The sequential ground motion effects on the dynamic responses of reinforced concrete containment (RCC) buildings with typical isolators are studied in this paper. Although the base isolation technique is developed to guarantee the security and integrity of RCC buildings under single earthquakes, seismic behavior of base-isolated RCC buildings under sequential ground motions is deficient. Hence, an ensemble of as-recorded sequential ground motions is employed to study the effect of including aftershocks on the seismic evaluation of base-isolated RCC buildings. The results indicate that base isolation can significantly attenuate the earthquake shaking of the RCC building under not only single earthquakes but also seismic sequences. It is also found that the adverse aftershock effect on the RCC can be reduced due to the base isolation applied to the RCC. More importantly, the study indicates that disregarding aftershocks can induce significant underestimation of the isolator displacement for base-isolated RCC buildings.
\end{abstract}

\section{Introduction}

Historical earthquakes show that mainshock-aftershock sequence-type ground motions are formed when frequent aftershocks occur after a strong mainshock [1]. Under the United States Geological Survey (USGS), a Mw8.6 earthquake occurred in Indonesia on April 11, 2012. After that, a great number of strong aftershocks happened and the largest magnitude attained 8.2. After the Tohoku-Oki earthquake with magnitude Mw9.0 occurring on March 11, 2011, in Japan, a large number of aftershocks struck the same area and the greatest one reached magnitude Mw7.9. Due to the potentially devastating effect of aftershocks, a great number of researchers attempted to investigate the effects of aftershocks on different structural systems, including the single-degreeof-freedom systems [2-10], reinforced concrete structures [11-18], steel structures [19-22], and wood-frame buildings [23-25]. As the last defense against nuclear leakage, the reinforced concrete containment (RCC) building subject to sequential ground motions is researched by [26]. It reveals that sequential ground motions can have adverse effects on the dynamic responses of the RCC including acceleration, displacements, and accumulated damage.

To deal with the variability of earthquakes, different types of isolation systems have been proposed and adopted for residential structures through the past twenty years. The isolation system has been applied to buildings [27, 28], bridges [29], and other types of structures, particularly in seismic areas with high intensity, such as Japan and California, USA. The isolators have also been employed to protect primary structures and nonstructural components for nuclear power plant (NPP). Using properly designed isolation systems and detailed three-dimensional numerical models, it is found by some researchers that seismic isolation can significantly reduce the seismic responses of NPP structures and nonstructural components [30-34]. To demonstrate the advantage of isolators for NPPs, other researchers adopted simple lumpedmass stick models [35-37]. However, these researches were mainly carried out by considering only mainshocks. Under mainshock-aftershock sequences, the effectiveness of base isolation for NPP structures and facilities may be decreased [38]. Moreover, in order to better guarantee the security and 


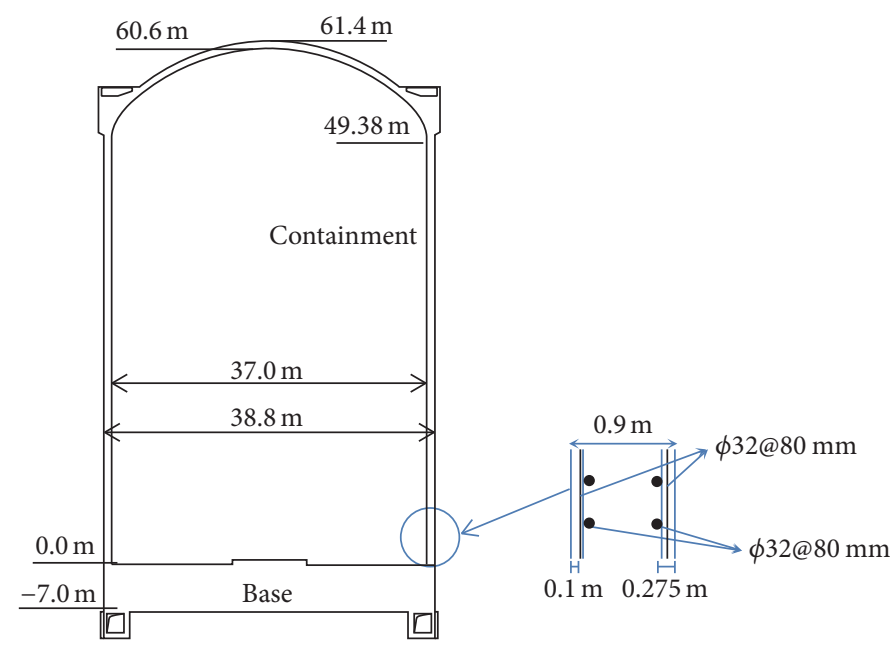

FIgURE 1: The sectional view of the analyzed RCC.

integrity of NPP structures and facilities, it is necessary and important to investigate the dynamic response of NPPs with base isolation and quantify the adverse aftershock effect and damaging aftershock sequences.

This paper is to study the effect of sequential ground motions on the seismic behavior of the RCC building with lead rubber bearing (LRB) isolators. To achieve this aim, finite element models for fixed-base and base-isolated RCC buildings are established employing the software ABAQUS 6.10 [39]. A group of as-recorded sequential ground motions is selected from the Pacific Earthquake Engineering Research (PEER) strong motion database [40]. The seismic analysis results including acceleration and displacements are compared between the RCC with and without isolators. Besides, the damaging aftershock sequence is also investigated and given in this manuscript.

\section{Structural Models}

2.1. The Fixed-Base RCC Building. Figure 1 shows a sectional view of the analyzed RCC building. The inside and outside diameters of the cylinder are $37 \mathrm{~m}$ and $38.8 \mathrm{~m}$, respectively. The height of the cylinder and the total height of the containment building are $49.38 \mathrm{~m}$ and $61.4 \mathrm{~m}$, respectively. The wall thickness of the dome is $0.8 \mathrm{~m}$. The elastic modulus, Poisson's ratio, density, tensile strength, and compressive strength of the containment concrete are assumed to be $36000 \mathrm{MPa}, 0.2$, $2400 \mathrm{~kg} / \mathrm{m}^{3}, 2.85 \mathrm{MPa}$, and $40 \mathrm{MPa}$, respectively. The yield strength of the steel is $350 \mathrm{MPa}$. The finite element model for the RCC building shown in Figure 2 is set up using ABAQUS 6.10 . Since the damaged plasticity model $[41,42]$ reflects the characteristics of cracking and crushing of concrete and is widely used in concrete structures, it is adopted here as the constitutive relation for concrete. In this model, the uniaxial strength functions are composed of plastic deformation and degradation of stiffness. Therefore, the tensile damage $(\mathrm{dt})$ and the compressive damage (dc) are addressed by normal strain at any point as shown in Figure 3. A bilinear restoring force is adopted for the rebars in the arranged direction, with

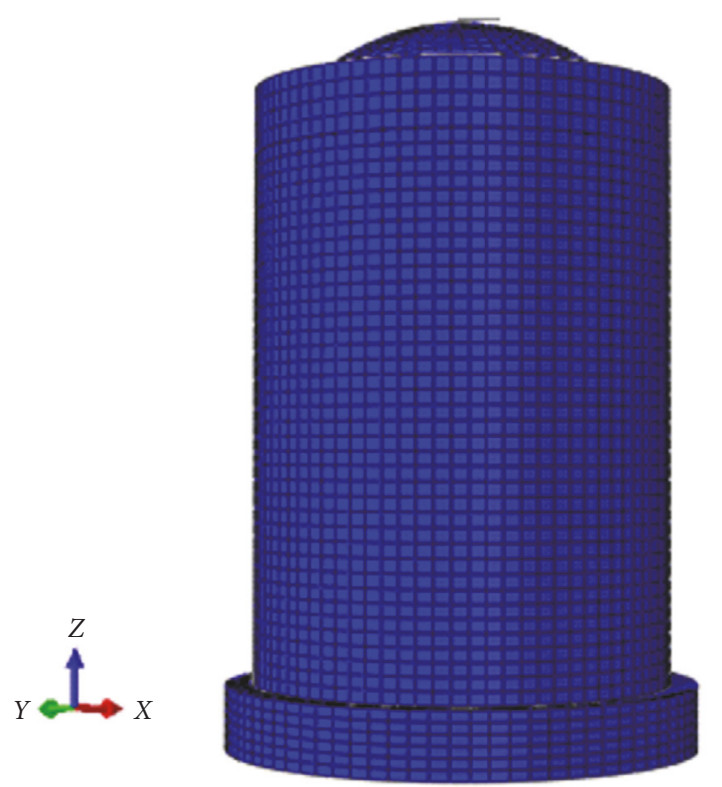

FIGURE 2: 3D finite element model for the fixed-base RCC.

the second gradient $1 / 100$ of the elastic stiffness supplied by a nuclear power group. The soil-structure interaction is not taken into account because the RCC building is located at a rock soil site. More detailed information about the RCC building can be found in [26].

2.2. The RCC Building with Isolators. Because the lead rubber bearing (LRB) system has all desirable features for base isolation and is widely used in engineering applications, it is adopted as isolation systems in this study. LRB is formed by force-fitting the lead plug into a preformed hole in the low damping elastomeric bearing as shown in Figure 4. The steel plates force the lead plug to deform in shear. Performance of LRB is maintained during repeated strong earthquakes with proper durability and reliability. LRB not only supplies the 


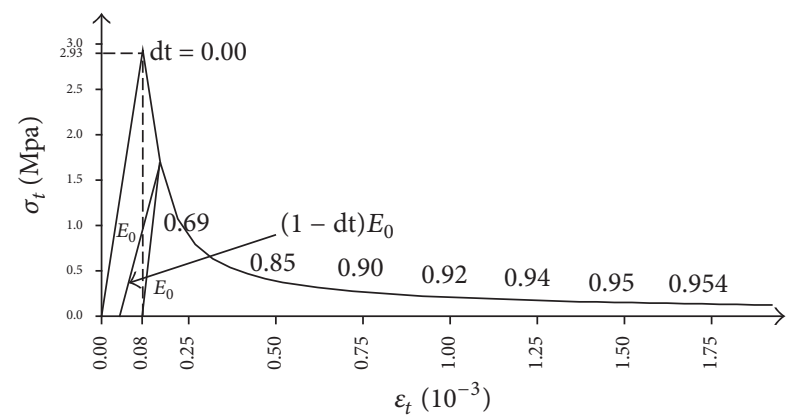

(a)

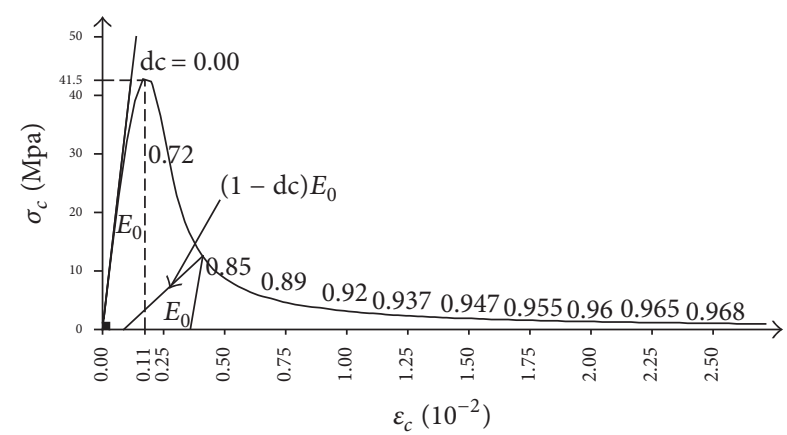

(b)

Figure 3: Assumed constitutive behavior of concrete in tension (a) and in compression (b).

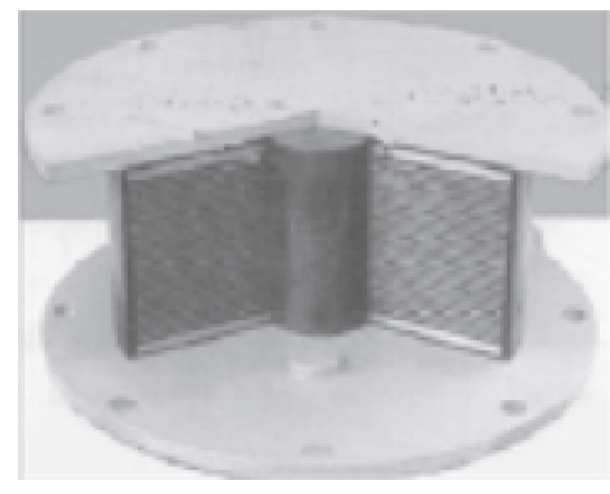

(a)

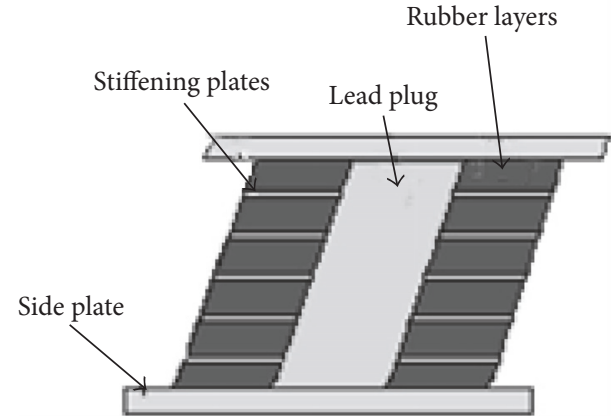

(b)

Figure 4: Lead rubber bearing (a) geometry and (b) deformation due to loading.

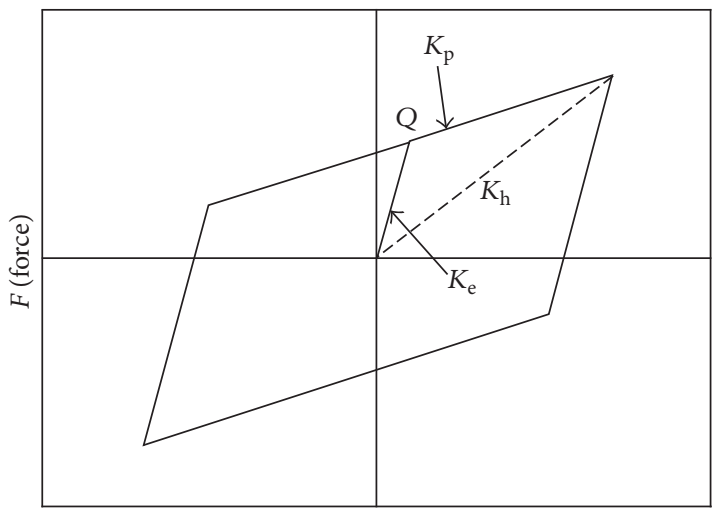

$\Delta$ (displacement or shear strain)

FIGURE 5: The bilinear force-displacement model for LRB isolators.

needed damping but also provides higher elastic stiffness. The seismic behavior for LRB is shown in Figure 5, in which $K_{\mathrm{e}}$ is the elastic stiffness, $K_{\mathrm{p}}$ the postyield stiffness, $K_{\mathrm{h}}$ the equivalent horizontal stiffness, and $Q$ the yield capacity. The hysteresis loop of the isolator is simulated according to the method recommended by [43]. The procedure for designing LRB isolators is conducted according to [44]. Firstly, according to Regulatory Guide 1.60 in Rev. 1, 1993 [45], the

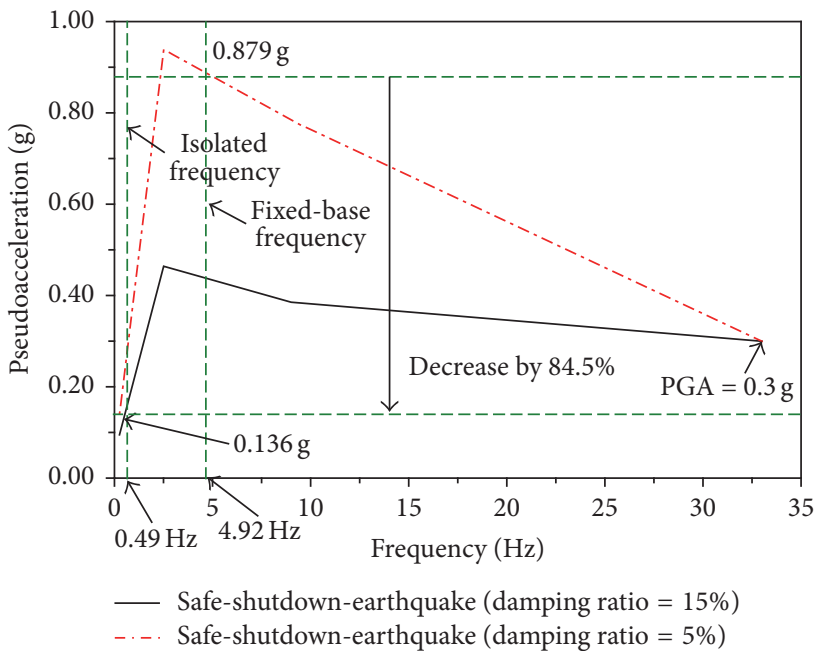

FIGURE 6: The safe-shutdown-earthquake event (peak ground acceleration is equal to $0.3 \mathrm{~g}$ ).

safe-shutdown-earthquake event (peak ground acceleration is equal to $0.3 \mathrm{~g}$ ), which is the maximum earthquake potential for which the RCC building is designed to sustain and remain functional, is determined, as shown in Figure 6. Due to the reduction demand for the design force $(75 \% \sim 85 \%)$ 


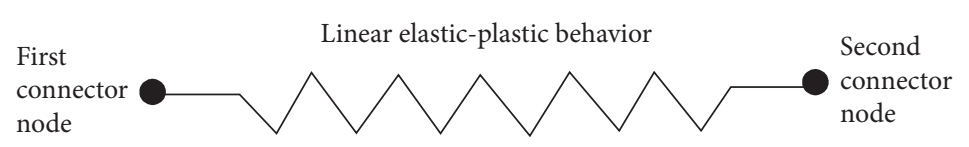

(a)

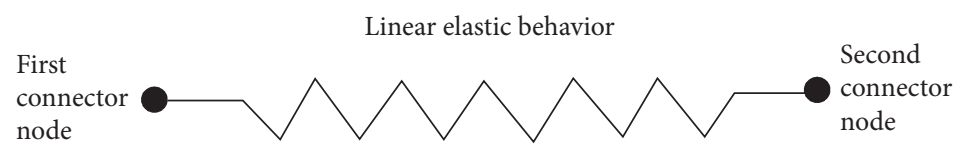

(b)

FIGURE 7: The modeling method of isolators for the horizontal direction (a) and vertical direction (b).

required by a nuclear power company, the isolator frequency is assumed to be $0.49 \mathrm{~Hz}$ and the damping ratio of the isolator 15\%. It can be also found from Figure 6 that the $S_{\mathrm{a}}$ value corresponding to the frequency and damping ratio is $0.136 \mathrm{~g}$ and the reduction of design force reaches $84.5 \%$. Then, the spectral displacement can be computed with the chosen isolation frequency and the damping ratio, as is shown in

$$
S_{\mathrm{d}}=\frac{S_{\mathrm{a}}}{\omega^{2}}
$$

where $S_{\mathrm{d}}$ and $S_{\mathrm{a}}$ are displacement and acceleration spectra, respectively, while $\omega$ is the chosen isolation frequency. Therefore, the calculated $S_{\mathrm{d}}$ is $140.7 \mathrm{~mm}$.

According to the base displacement represented by $S_{\mathrm{d}}$, the stiffness can be determined for each isolator. Next, a total of isolators are applied using

$$
\begin{aligned}
f_{i} & =\frac{1}{2 \pi} \sqrt{\frac{K_{\mathrm{RCC}-\text { total }}}{M_{\mathrm{RCC}}}}, \\
N_{\text {isolator }} & =\frac{\left(2 \pi f_{i}\right)^{2} M_{\mathrm{RCC}}}{K_{\mathrm{RCC}-i}},
\end{aligned}
$$

where $K_{\mathrm{RCC} \text {-total }}$ and $M_{\mathrm{RCC}}$ represent a total stiffness of isolators and a total mass of the structure equivalent to 3.71 $\times 10^{7} \mathrm{Kg} . K_{\mathrm{RCC}-i}$ is the stiffness of each isolator and $f_{i}$ is the selected isolation frequency. In this study, the LRB isolator having the design horizontal displacement at $100 \%$ shear strain of $140 \mathrm{~mm}$ and the allowable lateral displacement of $560 \mathrm{~mm}$ is selected. The elastic stiffness $\left(K_{\mathrm{e}}\right)$, the postyield stiffness $\left(K_{\mathrm{p}}\right)$ at $100 \%$ strain, and the yield capacity $(Q)$ are $7.60 \mathrm{kN} / \mathrm{mm}, 1.17 \mathrm{kN} / \mathrm{mm}$, and $66 \mathrm{kN}$, respectively. Then, a total of isolators equal to 251 are obtained and applied. The maximum load $\left(F_{y}\right)$ having $2100 \mathrm{kN}$ in the vertical direction for each isolator also satisfies the need of $1448 \mathrm{kN}$. Since ABAQUS 6.10 software provides the connector element which can be used to model the nonlinear behavior and the damping of isolators, the isolator is simulated using the element in this study. Specifically, the behavior of the isolator for the horizontal direction is modeled using the linear elastic-plastic behavior, as is shown in Figure 7(a). For the vertical direction, the elastic behavior is employed, as is shown in Figure 7(b). The finite element model for the baseisolated RCC building appears in Figure 8. The arrangement diagram of the isolators is displayed in Figure 9.

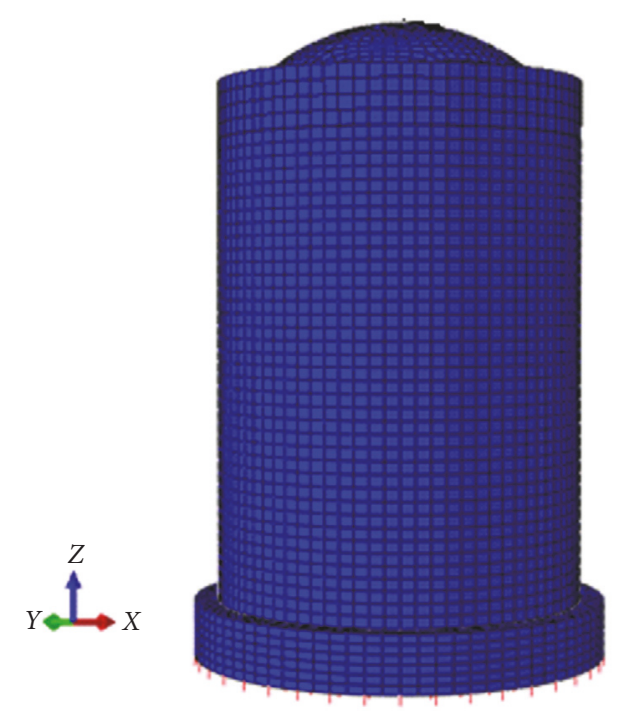

FIGURE 8: 3D finite element model of the base-isolated RCC.

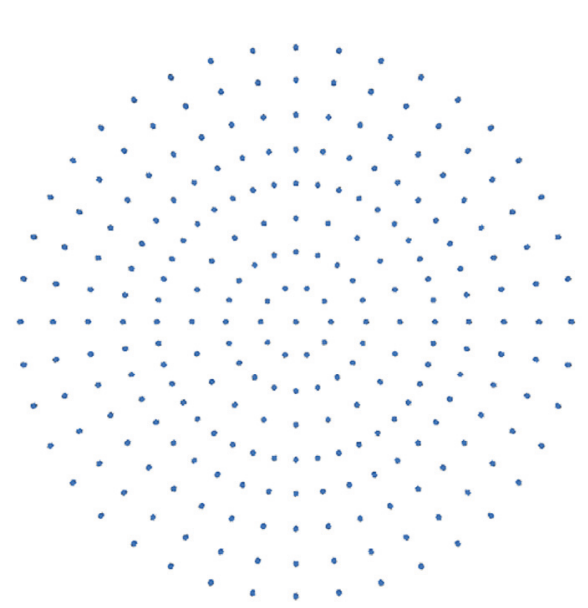

FIGURE 9: The layout of the isolators.

\section{Ground Motions}

In order to study the effect of sequential ground motions on the RCC with and without isolators, appropriate sequential ground motions must first be defined. Currently, a 
TABLE 1: Detailed information of selected seismic sequences.

\begin{tabular}{|c|c|c|c|c|c|c|c|}
\hline $\begin{array}{l}\text { Ground } \\
\text { motion }\end{array}$ & Time & Event & $\begin{array}{l}\text { Magnitude } \\
\text { (Ms) }\end{array}$ & $\begin{array}{l}\text { Vs30 } \\
(\mathrm{m} / \mathrm{s})\end{array}$ & Component & $\begin{array}{c}\text { Input } \\
\text { direction }\end{array}$ & PGA (g) \\
\hline \multirow{6}{*}{$\begin{array}{l}\text { Chi-Chi } \\
\text { Station: } \\
\text { CWB } 99999 \\
\text { TCU075 }\end{array}$} & \multirow{2}{*}{ 09/20/99 } & \multirow{2}{*}{ Mainshock } & \multirow{2}{*}{7.62} & \multirow{2}{*}{573} & $\mathrm{E}$ & $X$ & 0.33 \\
\hline & & & & & $\mathrm{N}$ & $Y$ & 0.26 \\
\hline & \multirow{2}{*}{$09 / 20 / 99$} & \multirow{2}{*}{ Aftershock-1 } & \multirow{2}{*}{6.2} & \multirow{2}{*}{573} & $\mathrm{E}$ & $X$ & 0.22 \\
\hline & & & & & $\mathrm{N}$ & $Y$ & 0.15 \\
\hline & \multirow{2}{*}{$09 / 25 / 99$} & \multirow{2}{*}{ Aftershock-2 } & \multirow{2}{*}{5.9} & \multirow{2}{*}{573} & $\mathrm{E}$ & $X$ & 0.11 \\
\hline & & & & & $\mathrm{N}$ & $Y$ & 0.06 \\
\hline \multirow{4}{*}{$\begin{array}{l}\text { Irpinia } \\
\text { Station: Calitri }\end{array}$} & $1980 / 11 / 23$ & \multirow{2}{*}{ Mainshock } & \multirow{2}{*}{6.9} & \multirow{2}{*}{600} & 000 & $X$ & 0.132 \\
\hline & 19:34 & & & & 270 & $Y$ & 0.176 \\
\hline & $1980 / 11 / 23$ & \multirow{2}{*}{ Aftershock } & \multirow{2}{*}{6.2} & \multirow{2}{*}{600} & 000 & $X$ & 0.177 \\
\hline & 19:35 & & & & 270 & $Y$ & 0.165 \\
\hline \multirow{4}{*}{$\begin{array}{l}\text { Whittier } \\
\text { Station: } 24399 \mathrm{Mt} \\
\text { Wilson - CIT } \\
\text { Seis Sta }\end{array}$} & \multirow{2}{*}{$10 / 01 / 87$} & \multirow{2}{*}{ Mainshock } & \multirow{2}{*}{6.0} & 821.7 & 000 & $X$ & 0.123 \\
\hline & & & & & 090 & $Y$ & 0.186 \\
\hline & $10 / 04 / 87$ & Aftershock & 5.3 & 8217 & 000 & $X$ & 0.158 \\
\hline & & Altersnock & 5.3 & & 090 & $Y$ & 0.142 \\
\hline Irninia & $1980 / 11 / 23$ & Mainshock & 6.9 & 530 & 000 & $X$ & 0.106 \\
\hline Station: Rionero & 19:34 & IVIAHISHOCK & 0.9 & 300 & 270 & $Y$ & 0.104 \\
\hline In Vulture & $1980 / 11 / 23$ & Aftershock & 62 & 530 & 000 & $X$ & 0.099 \\
\hline & 19:35 & 月1, & 0.2 & 300 & 270 & $Y$ & 0.096 \\
\hline Coalinga & $1983 / 07 / 22$ & Mainshock & 577 & 6174 & 000 & $X$ & 0.141 \\
\hline Station: 1703 & 02:39 & VIdIISIIOCK & (3.17 & $01 \% .4$ & 090 & $Y$ & 0.127 \\
\hline Sulphur Baths & $1983 / 07 / 25$ & Aftershock & 5.21 & 617.4 & 000 & $X$ & 0.152 \\
\hline & 22:31 & & & & 090 & $Y$ & 0.23 \\
\hline Mammoth Lakes & $1980 / 05 / 25$ & Mainshock & 6.06 & 370.8 & 270 & $X$ & 0.321 \\
\hline Station: 54301 & $16: 34$ & NIAIISHOCK & 0.00 & $3 / 0.0$ & 360 & $Y$ & 0.239 \\
\hline Mammoth Lakes & $1980 / 05 / 25$ & Aftershock & 569 & 3708 & 270 & $X$ & 0.39 \\
\hline H. S. & $16: 49$ & Ailersnock & 3.09 & $3 / 0.8$ & 360 & $Y$ & 0.441 \\
\hline Mammoth Lakes & $1980 / 05 / 31$ & Mainshock & 48 & 4722 & 180 & $X$ & 0.196 \\
\hline Station: 42 & $15: 16$ & & & & 270 & $Y$ & 0.206 \\
\hline Convict Lakes & $1980 / 06 / 11$ & Aftershock & 4.85 & 4722 & 180 & $X$ & 0.191 \\
\hline$(\mathrm{CON})$ & 04:41 & 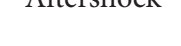 & $4.0 \mathrm{~J}$ & $4 / 2.2$ & 270 & $Y$ & 0.183 \\
\hline Whittier & $10 / 01 / 87$ & Mainshock & 60 & 550 & 180 & $X$ & 0.333 \\
\hline Station: 24461 & - $10 / 01 / 0 \%$ & NHaHISHOC & 0.0 & (50 & 270 & $Y$ & 0.414 \\
\hline Alhambra, & $10 / 04 / 87$ & Aftershock & 53 & 550 & 180 & $X$ & 0.174 \\
\hline Fremont Sch & $10 / 04 / 07$ & АНЕТSНОСК & $0 . J$ & 350 & 270 & $Y$ & 0.178 \\
\hline Whittier & $10 / 01 / 87$ & Mainshock & 6.0 & 375.2 & 000 & $X$ & 0.299 \\
\hline Station: 24402 & & & & & 090 & $Y$ & 0.151 \\
\hline Altadena - Eaton & $10 / 04 / 87$ & Aftershock & 5.3 & 375.2 & 000 & $X$ & 0.264 \\
\hline Canyon & & & & & 090 & $Y$ & 0.199 \\
\hline Whittier & $10 / 01 / 87$ & Mainshock & 6.0 & 379.4 & 270 & $X$ & 0.128 \\
\hline Station: 24401 San & & & & & 360 & $Y$ & 0.204 \\
\hline Marino, SW & $10 / 04 / 87$ & Aftershock & 53 & 3794 & 270 & $X$ & 0.156 \\
\hline Academy & $10 / 04 / 0 \%$ & & 0.0 & & 360 & $Y$ & 0.212 \\
\hline
\end{tabular}

sequential ground motion can be reproduced mainly using three approaches: the repeated approach [2], the randomized approach [9], and as-recorded sequential ground motions. In this study, as-recorded sequential ground motions including the mainshock and at least one aftershock are employed for carrying out nonlinear time history analyses since those seismic sequences represent the real correlation between the mainshock and the aftershock and would not overestimate the structural response significantly in comparison with artificial seismic sequences [22]. In this study, seismic sequences are selected according to the following criteria: (a) magnitudes of most mainshocks are close to or greater than 6.0 and most major aftershocks are equal to or greater than 5.0; (b) accelerograms are recorded by stations which are located in free field; (c) peak ground acceleration of major aftershocks and mainshocks are equal to or greater than $0.1 \mathrm{~g}$; (d) accelerograms are recorded on rock or stiff soil. Under these criteria, twenty as-recorded mainshock-aftershock seismic sequences, which have been recorded during a short period of time, by the same station, are downloaded from the strong motion database of PEER [40]. Table 1 presents the detailed information of selected mainshock-aftershock 
TABLE 2: Results for modal analysis.

\begin{tabular}{|c|c|c|c|c|c|c|}
\hline \multirow{3}{*}{ Mode number } & \multicolumn{3}{|c|}{ Fixed-base RCC } & \multicolumn{3}{|c|}{ RCC with isolators } \\
\hline & \multirow{2}{*}{$\begin{array}{l}\text { Frequency } \\
\quad(\mathrm{Hz})\end{array}$} & \multicolumn{2}{|c|}{ Effective mass coefficient } & \multirow{2}{*}{$\begin{array}{c}\text { Frequency } \\
(\mathrm{Hz})\end{array}$} & \multicolumn{2}{|c|}{ Effective mass coefficient } \\
\hline & & $X$ & $Y$ & & $X$ & $Y$ \\
\hline (1) & 4.92 & $77.1 \%$ & 0 & 0.49 & $100 \%$ & 0 \\
\hline (2) & 4.92 & 0 & $77.1 \%$ & 0.49 & 0 & $100 \%$ \\
\hline (3) & 6.85 & 0 & 0 & 0.56 & 0 & 0 \\
\hline (4) & 6.86 & 0 & 0 & 5.04 & 0 & 0 \\
\hline (5) & 8.18 & 0 & 0 & 5.04 & 0 & 0 \\
\hline (6) & 8.21 & 0 & 0 & 6.95 & 0 & 0 \\
\hline (7) & 8.72 & 0 & 0 & 6.95 & 0 & 0 \\
\hline (8) & 8.72 & 0 & 0 & 8.28 & 0 & 0 \\
\hline (9) & 10.67 & 0 & 0 & 8.32 & 0 & 0 \\
\hline (10) & 12.74 & 0 & 0 & 8.87 & 0 & 0 \\
\hline (11) & 12.75 & 0 & 0 & 8.87 & 0 & 0 \\
\hline (12) & 13.63 & 0 & 0 & 12.98 & 0 & 0 \\
\hline (13) & 13.64 & 0 & 0 & 12.98 & 0 & 0 \\
\hline (14) & 14.06 & 0 & 0 & 13.87 & 0 & 0 \\
\hline (15) & 14.09 & 0 & 0 & 13.88 & 0 & 0 \\
\hline (16) & 14.34 & 0 & 0 & 14.26 & 0 & 0 \\
\hline (17) & 15.29 & 0 & 0 & 14.27 & 0 & 0 \\
\hline (18) & 15.29 & 0 & 0 & 14.56 & 0 & 0 \\
\hline (19) & 15.59 & $20.1 \%$ & 0 & 15.33 & 0 & 0 \\
\hline (20) & 15.60 & 0 & $20.1 \%$ & 15.33 & 0 & 0 \\
\hline Total & & $97.1 \%$ & $97.1 \%$ & & $100 \%$ & $100 \%$ \\
\hline
\end{tabular}

seismic sequences. Each of the aforementioned sequential motions has been separated into a single ground motion where a 100s gap is applied between two consecutive seismic events. This gap has zero acceleration ordinates and is sufficient to allow the structure to cease moving after the previous event. In order to represent the seismic hazard and maintain the same correlation between the mainshock and the aftershock, all the sequential ground motions are scaled to make peak ground acceleration (PGA) of mainshocks equal the safe-shutdown-earthquake level of $0.3 \mathrm{~g}$, and the relevant aftershocks are multiplied with the same amplitude factor like the mainshocks. It should be noted that the relationship between the mainshock and the aftershock is beyond the scope of this research and is not considered in this paper.

\section{Results and Discussion}

4.1. Results for Modal Analysis. The results from the nonlinear dynamic analyses can be analyzed with the aid of modal analysis results. Hence, free vibration analysis is firstly conducted for RCC buildings with and without isolators and the first 20 natural frequencies are shown in Table 2. It shows that for the fixed-base RCC the effective mass participations in $X$ and $Y$ direction are in the order of $77.1 \%$ for the first mode and second mode and $20.1 \%$ for the 19th mode and 20th mode while they are in the order 100\% for the first and second modes for the base-isolated RCC. It means that the dynamic behavior for both types of RCC is mainly controlled by the fundamental mode. Furthermore, it is expected that the isolation system would lead to greater decreases in seismic demands of the RCC on the basis of the target spectra [45] because it reduces the fundamental frequency of the RCC from $4.92 \mathrm{~Hz}$ to $0.49 \mathrm{~Hz}$. It is also found from Figure 10 that the fundamental mode for the fixed-base RCC is strongly dependent on lateral movements of the structure, whereas it is associated with pure translation movements of the isolator for the base-isolated RCC.

4.2. Acceleration Response. Nonstructural components like facilities located on the structure can be categorized into two parts: acceleration-sensitive and displacement-sensitive. For acceleration-sensitive facilities, their seismic performance must be justified using structural acceleration responses. This part quantifies the benefit of base isolation on accelerationsensitive facilities under seismic sequence excitations. Maximum top acceleration of the RCCs with and without isolators under mainshocks and seismic sequences appears in Table 3. Table 3 also presents the relative intensity of aftershock ground motions $\left(\mathrm{PGA}_{\mathrm{AS}} / \mathrm{PGA}_{\mathrm{MS}}\right)$ and the decreasing amplitude ratio (DAR) [34]. The relative intensity of aftershock ground motions is defined as the ratio of PGA for the aftershock to that for the mainshock $\left(\mathrm{PGA}_{\mathrm{AS}} / \mathrm{PGA}_{\mathrm{MS}}\right)$. The decreasing amplitude ratio (DAR) is employed to evaluate 
TABLE 3: Maximum top accelerations for the RCCs.

\begin{tabular}{|c|c|c|c|c|c|c|c|}
\hline \multirow{2}{*}{ Ground motion number } & \multirow{2}{*}{$\mathrm{PGA}_{\mathrm{AS}} / \mathrm{PGA}_{\mathrm{MS}}$} & \multicolumn{3}{|c|}{ Mainshock $\left(\mathrm{m} / \mathrm{s}^{2}\right)$} & \multicolumn{3}{|c|}{ Seismic sequence $\left(\mathrm{m} / \mathrm{s}^{2}\right)$} \\
\hline & & Fixed-base & Base-isolated & DAR & Fixed-base & Base-isolated & DAR \\
\hline (1) & 1.219 & 17.04 & 1.33 & $92.2 \%$ & 17.04 & 1.36 & $92.0 \%$ \\
\hline (2) & 1.039 & 14.30 & 2.26 & $84.2 \%$ & 16.65 & 2.26 & $86.5 \%$ \\
\hline (3) & 0.523 & 18.68 & 2.28 & $87.8 \%$ & 18.68 & 2.28 & $87.8 \%$ \\
\hline (4) & 0.430 & 7.91 & 1.21 & $84.7 \%$ & 7.91 & 1.21 & $84.7 \%$ \\
\hline (5) & 1.215 & 11.29 & 0.81 & $92.8 \%$ & 11.29 & 0.81 & $92.8 \%$ \\
\hline (6) & 1.845 & 14.69 & 1.52 & $89.6 \%$ & 20.89 & 2.13 & $89.8 \%$ \\
\hline (7) & 0.974 & 14.02 & 1.04 & $92.6 \%$ & 14.02 & 1.04 & $92.6 \%$ \\
\hline (8) & 0.888 & 13.05 & 0.79 & $93.9 \%$ & 13.25 & 0.79 & $94.0 \%$ \\
\hline (9) & 0.934 & 17.18 & 2.86 & $83.3 \%$ & 17.18 & 2.86 & $83.3 \%$ \\
\hline (10) & 0.923 & 16.61 & 3.23 & $80.5 \%$ & 16.61 & 3.23 & $80.5 \%$ \\
\hline (11) & 1.078 & 4.59 & 1.67 & $63.6 \%$ & 8.19 & 1.67 & $79.6 \%$ \\
\hline (12) & 1.811 & 8.85 & 1.53 & $82.7 \%$ & 20.39 & 3.46 & $83.1 \%$ \\
\hline (13) & 0.883 & 12.71 & 1.46 & $88.5 \%$ & 12.71 & 1.46 & $88.5 \%$ \\
\hline (14) & 1.318 & 11.55 & 0.89 & $92.3 \%$ & 17.08 & 1.28 & $92.5 \%$ \\
\hline (15) & 1.341 & 14.21 & 4.65 & $67.3 \%$ & 17.54 & 4.65 & $73.5 \%$ \\
\hline (16) & 0.938 & 13.99 & 3.77 & $73.1 \%$ & 14.98 & 3.77 & $74.9 \%$ \\
\hline (17) & 0.667 & 15.85 & 2.16 & $86.4 \%$ & 15.85 & 2.16 & $86.4 \%$ \\
\hline (18) & 0.577 & 14.15 & 2.25 & $84.1 \%$ & 14.15 & 2.25 & $84.1 \%$ \\
\hline (19) & 1.285 & 13.83 & 1.19 & $91.4 \%$ & 13.89 & 1.33 & $90.4 \%$ \\
\hline (20) & 0.763 & 10.47 & 0.89 & $91.5 \%$ & 10.47 & 0.89 & $91.5 \%$ \\
\hline Average & 1.033 & 13.25 & 1.89 & $85.7 \%$ & 14.93 & 2.04 & $86.3 \%$ \\
\hline
\end{tabular}

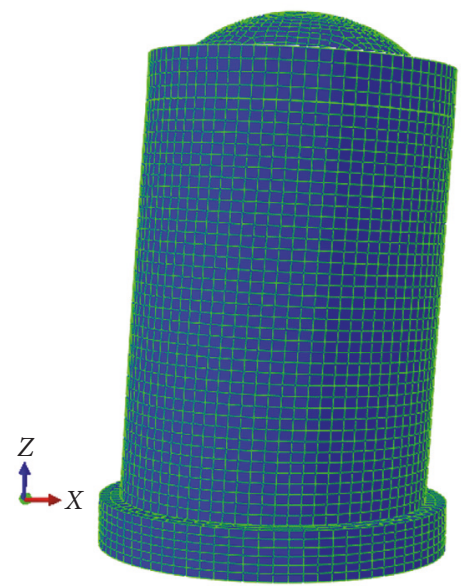

(a)

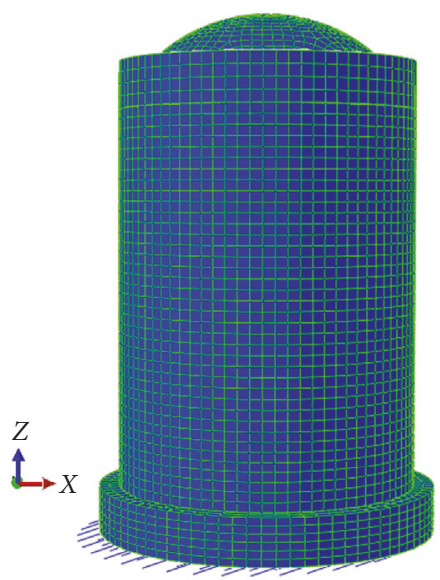

(b)

FIGURE 10: The first mode shape of the nonisolated RCC (a) and the base-isolated RCC (b).

the effectiveness of the isolation system in the RCC. The expression of DAR is defined as follows:

$$
\mathrm{DAR}=\frac{\left(\mathrm{SR}_{\mathrm{N}}-\mathrm{SR}_{\mathrm{I}}\right)}{\mathrm{SR}_{\mathrm{N}}} \times 100 \%,
$$

where $\mathrm{SR}_{\mathrm{N}}$ and $\mathrm{SR}_{\mathrm{I}}$ are structural responses without and with isolation, respectively.

It can be seen in Table 3 that, in comparison with the fixed-base RCC, average maximum absolute acceleration of the isolated RCC reduces by up to $85.7 \%$ under mainshocks and $86.3 \%$ under multiple ground motions. This demonstrates that base isolation can result in decreased acceleration demands for structures under both single and sequential earthquakes. It is also found from Table 3 that the average $\mathrm{PGA}_{\mathrm{AS}} / \mathrm{PGA}_{\mathrm{MS}}$ is approximate to 1 , indicating that the average intensity of aftershocks is equal to that of mainshocks. Indeed, one of the most concern problems for the structural and nuclear engineers is the seismic performance of the RCC building under an aftershock with 


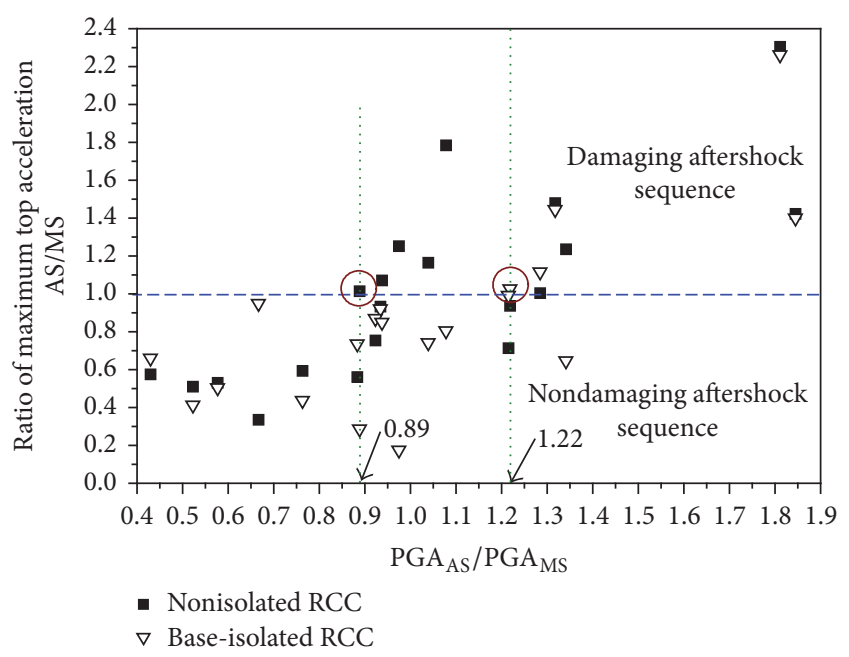

FIgURE 11: Ratio of maximum top acceleration as function of $\mathrm{PGA}_{\mathrm{AS}} / \mathrm{PGA}_{\mathrm{MS}}$.

the same or even higher intensity than the corresponding mainshock. In Table 3, the average maximum acceleration for the fixed-base RCC increases from $13.25 \mathrm{~m} / \mathrm{s}^{2}$ to $14.93 \mathrm{~m} / \mathrm{s}^{2}$, rising by $12.7 \%$ due to the multiplicity of earthquakes. This increase cannot be neglected for seismic design of facilities. In contrast, the increase of average maximum acceleration for the base-isolated RCC is from $1.89 \mathrm{~m} / \mathrm{s}^{2}$ under mainshocks to $2.04 \mathrm{~m} / \mathrm{s}^{2}$ under seismic sequences, only rising by $7.9 \%$ which is much lower in comparison with the fixed-base RCC. It should also be noted that Coalinga seismic sequence (number (12)) with the $P G A_{A S} / P A_{M S}$ equal to 1.81 has induced the largest acceleration increase $\left(11.54 \mathrm{~m} / \mathrm{s}^{2}\right)$ for the fixed-base RCC, while the increase for the base-isolated RCC has only $1.93 \mathrm{~m} / \mathrm{s}^{2}$. Obtained results indicate that the base isolation can be applied to the RCC to reduce the seismic shaking of the RCC and to facilitate the standardization of facility designs for seismic sequences.

The main characteristics of damaging aftershock sequences for both base-isolated and fixed-base RCCs are further investigated in this part. The damaging aftershock sequences are labeled as those resulting in larger responses (i.e., acceleration or displacement responses) of the RCC due to aftershocks. Figure 11 presents the ratio of the maximum top acceleration for the aftershock (AS) to that for the mainshock (MS) as function of $\mathrm{PGA}_{\mathrm{AS}} / \mathrm{PGA}_{\mathrm{MS}}$. The figure shows that, for the fixed-base RCC, 9 of the 20 records lead to the ratio of maximum top acceleration more than 1 , indicating that $45 \%$ of the cases are damaging aftershock sequences. Compared with the fixed-base RCC, the number of records resulting in greater aftershock acceleration responses is 5 for the base-isolated RCC, only accounting for $25 \%$ of the cases. It is also noted that when the $\mathrm{PGA}_{\mathrm{AS}} / \mathrm{PGA}_{\mathrm{MS}}$ is more than 0.89 , the aftershocks would result in greater acceleration responses for the fixed-base RCC. By contrast, the baseisolated RCC would not be exposed to greater dynamic forces due to aftershocks unless the $\mathrm{PGA}_{\mathrm{AS}} / \mathrm{PGA}_{\mathrm{MS}}$ is more than 1.22. It can be concluded that the adverse effect of aftershock sequences would be decreased due to the base isolation applied to the RCC.

The ratio of the mean response spectra for the mainshockaftershock (MSAS) to those for the mainshock is displayed in Figure 12. Figure 12(a) shows that, for the fixed-base RCC, the ratios of damaging aftershock sequences are greater between the vibration period of $0 \mathrm{~s}$ and $0.52 \mathrm{~s}$ while being lower between the vibration period of $0.52 \mathrm{~s}$ and $6 \mathrm{~s}$ in comparison with those of nondamaging sequences. The ratio for damaging aftershock sequences at the first period of the structure $(0.2 \mathrm{~s})$ is 1.48 , reaching 1.31 times as large as that of nondamaging sequences. It reveals that the damaging aftershock sequence for the fixed-base RCC is more associated with greater aftershock response spectral values around the structural period $(0.2 \mathrm{~s})$ of the RCC. Similar results can be obtained for the base-isolated RCC, as shown in Figure 12(b). Additionally, it is noteworthy from Figure 12(b) that the damaging aftershock sequence for the base-isolated RCC has no direct relevance with the aftershock response spectral values around the isolation frequency $(0.49 \mathrm{~Hz})$.

4.3. Displacement Response. The displacement demands for both superstructures and isolators are analytically studied in this section. The displacement demands are determined as maximum relative displacements.

4.3.1. Superstructure. Table 4 shows the maximum relative displacements of the superstructure between the top point and the base under single and multiple ground motions. As can be seen from Table 4, compared with the fixedbase RCC, average maximum relative displacements for the isolated RCC reduce by up to $84.9 \%$ and $86.6 \%$, respectively, under mainshocks and sequential ground motions. Though the average $\mathrm{PGA}_{\mathrm{AS}} / \mathrm{PGA}_{\mathrm{MS}}$ is close to 1 , the average maximum relative displacement for the fixed-base RCC rises by $21.4 \%$, growing from $0.0210 \mathrm{~m}$ under mainshocks to $0.0255 \mathrm{~m}$ under seismic sequences, while no difference of the average maximum relative displacement for the base-isolated RCC can be found between mainshocks and multiple ground motions. It should be mentioned that Coalinga seismic sequence (number (12)) induces the largest displacement increase $(0.015 \mathrm{~m})$ for the fixed-base RCC in comparison with the corresponding mainshock while the increase is only $0.003 \mathrm{~m}$ for the base-isolated RCC. Obtained results indicate that isolators can not only reduce the structural deformation significantly but also prevent strong aftershocks from causing more permanent deformation to the structure.

In order to further research the main characteristics of damaging aftershock sequences corresponding to maximum relative displacement for both base-isolated and fixed-base RCCs, the ratio of the maximum relative displacement for the aftershock to that for the mainshock only is displayed in Figure 13 as function of $\mathrm{PGA}_{\mathrm{AS}} / \mathrm{PGA}_{\mathrm{MS}}$. In Figure 13, for the fixed-base RCC, 10 records result in greater aftershock displacement responses, making up 50\% of the cases. For the base-isolated RCC, the percentage of damaging aftershock sequences decreases to $20 \%$. Additionally, the RCC may suffer additional displacements from aftershocks when $\mathrm{PGA}_{\mathrm{AS}} / \mathrm{PGA}_{\mathrm{MS}}$ is more than 0.94 for the fixed-base RCC 
TABLE 4: Maximum relative displacements for the RCCs.

\begin{tabular}{|c|c|c|c|c|c|c|c|}
\hline \multirow{2}{*}{ Ground motion number } & \multirow{2}{*}{$\mathrm{PGA}_{\mathrm{AS}} / \mathrm{PGA}_{\mathrm{MS}}$} & \multicolumn{3}{|c|}{ Mainshock (m) } & \multicolumn{3}{|c|}{ Seismic sequence $(\mathrm{m})$} \\
\hline & & Fixed-base & Base-isolated & DAR & Fixed-base & Base-isolated & DAR \\
\hline (1) & 1.219 & 0.024 & 0.002 & $91.2 \%$ & 0.032 & 0.003 & $91.8 \%$ \\
\hline (2) & 1.039 & 0.019 & 0.004 & $78.9 \%$ & 0.032 & 0.004 & $87.7 \%$ \\
\hline (3) & 0.523 & 0.031 & 0.004 & $87.9 \%$ & 0.031 & 0.004 & $87.9 \%$ \\
\hline (4) & 0.430 & 0.014 & 0.002 & $86.9 \%$ & 0.014 & 0.002 & $86.9 \%$ \\
\hline (5) & 1.215 & 0.013 & 0.001 & $89.1 \%$ & 0.013 & 0.001 & $89.1 \%$ \\
\hline (6) & 1.845 & 0.025 & 0.002 & $90.9 \%$ & 0.042 & 0.003 & $92.2 \%$ \\
\hline (7) & 0.974 & 0.012 & 0.002 & $85.7 \%$ & 0.019 & 0.002 & $90.5 \%$ \\
\hline (8) & 0.888 & 0.011 & 0.001 & $86.8 \%$ & 0.011 & 0.001 & $86.8 \%$ \\
\hline (9) & 0.934 & 0.033 & 0.005 & $84.7 \%$ & 0.033 & 0.005 & $84.7 \%$ \\
\hline (10) & 0.923 & 0.035 & 0.005 & $86.1 \%$ & 0.035 & 0.005 & $86.1 \%$ \\
\hline (11) & 1.078 & 0.007 & 0.003 & $57.0 \%$ & 0.015 & 0.003 & $80.9 \%$ \\
\hline (12) & 1.811 & 0.014 & 0.002 & $82.2 \%$ & 0.029 & 0.005 & $82.7 \%$ \\
\hline (13) & 0.883 & 0.014 & 0.002 & $82.1 \%$ & 0.014 & 0.002 & $82.1 \%$ \\
\hline (14) & 1.318 & 0.016 & 0.002 & $90.5 \%$ & 0.021 & 0.002 & $89.6 \%$ \\
\hline (15) & 1.341 & 0.032 & 0.008 & $76.1 \%$ & 0.040 & 0.008 & $81.1 \%$ \\
\hline (16) & 0.938 & 0.028 & 0.006 & $77.6 \%$ & 0.033 & 0.006 & $80.8 \%$ \\
\hline (17) & 0.667 & 0.031 & 0.004 & $86.3 \%$ & 0.031 & 0.004 & $86.3 \%$ \\
\hline (18) & 0.577 & 0.029 & 0.004 & $86.9 \%$ & 0.029 & 0.004 & $86.9 \%$ \\
\hline (19) & 1.285 & 0.017 & 0.002 & $88.2 \%$ & 0.021 & 0.002 & $90.4 \%$ \\
\hline$(20)$ & 0.763 & 0.014 & 0.001 & $89.8 \%$ & 0.014 & 0.001 & $89.8 \%$ \\
\hline Average & 1.033 & 0.0210 & 0.003 & $84.9 \%$ & 0.0255 & 0.003 & $86.6 \%$ \\
\hline
\end{tabular}

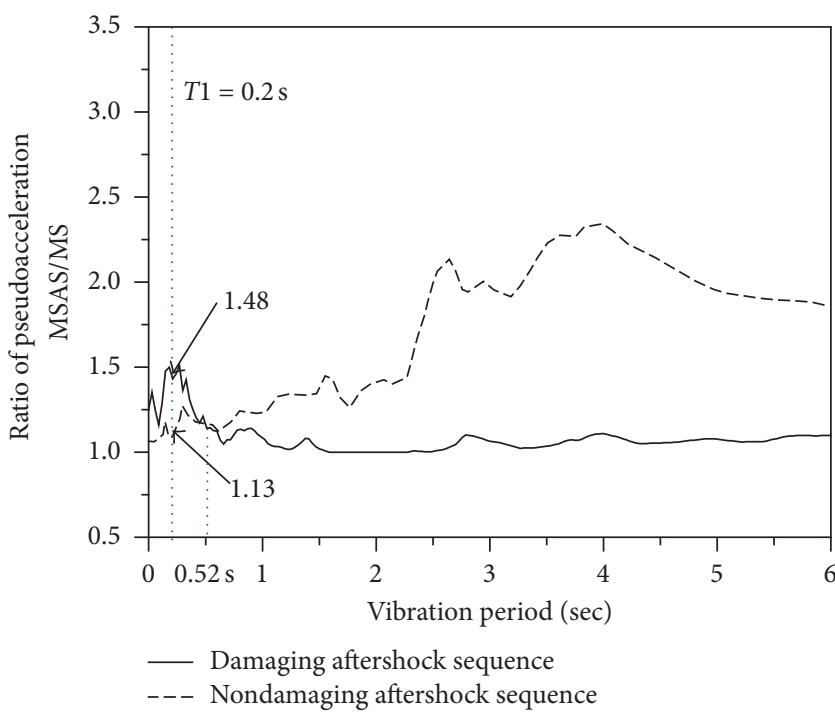

(a)

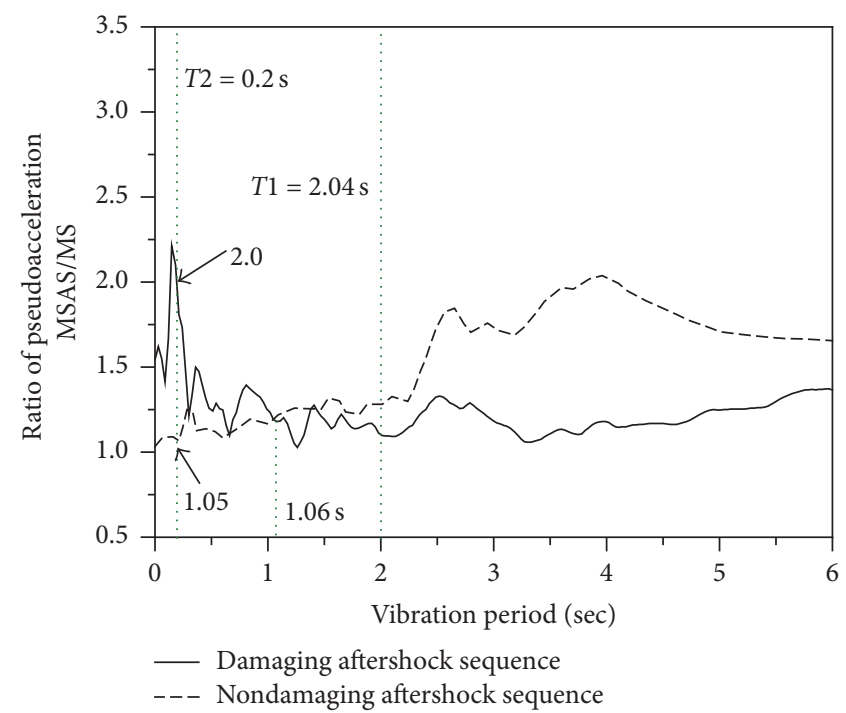

(b)

FIGURE 12: Ratio of response spectral statistics due to MSAS and MS record data for damaging and nondamaging sequences corresponding to top acceleration: (a) nonisolated RCC; (b) base-isolated RCC.

while being 1.22 for the RCC with isolators. It is demonstrated that the base isolation plays an important part in reducing the adverse aftershock effect on the RCC.

Figure 14 shows the ratio of the mean response spectra for the mainshock-aftershock to those for the mainshock. It can be seen from Figure 14 that damaging aftershock sequences, which refer to greater maximum relative displacements due to aftershocks in comparison with mainshocks, are more dependent on greater aftershock response spectral values around the structural period $(0.2 \mathrm{~s})$ of the RCC. The similar conclusion is observed for the maximum top acceleration response as mentioned in Section 4.2. Further observing Figure 14(b), it is found that while the ratio at $0.2 \mathrm{~s}$ for damaging aftershock sequences is 1.71 times greater than that 
TABLE 5: Maximum isolator displacements of the base-isolated RCC.

\begin{tabular}{|c|c|c|c|}
\hline \multirow{2}{*}{ Ground motion number } & \multirow{2}{*}{$\mathrm{PGA}_{\mathrm{AS}} / \mathrm{PGA}_{\mathrm{MS}}$} & \multicolumn{2}{|c|}{ Maximum isolator displacement $(\mathrm{m})$} \\
\hline & & Mainshock & Seismic sequence \\
\hline$(1)$ & 1.219 & 0.022 & 0.048 \\
\hline$(2)$ & 1.039 & 0.060 & 0.060 \\
\hline (3) & 0.523 & 0.048 & 0.048 \\
\hline$(4)$ & 0.430 & 0.022 & 0.022 \\
\hline$(5)$ & 1.215 & 0.022 & 0.024 \\
\hline$(6)$ & 1.845 & 0.025 & 0.038 \\
\hline (7) & 0.974 & 0.010 & 0.010 \\
\hline$(8)$ & 0.888 & 0.014 & 0.014 \\
\hline (9) & 0.934 & 0.048 & 0.118 \\
\hline$(10)$ & 0.923 & 0.036 & 0.064 \\
\hline (11) & 1.078 & 0.027 & 0.054 \\
\hline$(12)$ & 1.811 & 0.020 & 0.043 \\
\hline (13) & 0.883 & 0.025 & 0.025 \\
\hline$(14)$ & 1.318 & 0.019 & 0.019 \\
\hline$(15)$ & 1.341 & 0.144 & 0.144 \\
\hline (16) & 0.938 & 0.107 & 0.189 \\
\hline (17) & 0.667 & 0.135 & 0.155 \\
\hline (18) & 0.577 & 0.039 & 0.039 \\
\hline (19) & 1.285 & 0.015 & 0.015 \\
\hline$(20)$ & 0.763 & 0.008 & 0.008 \\
\hline Average & 1.033 & 0.042 & 0.057 \\
\hline
\end{tabular}

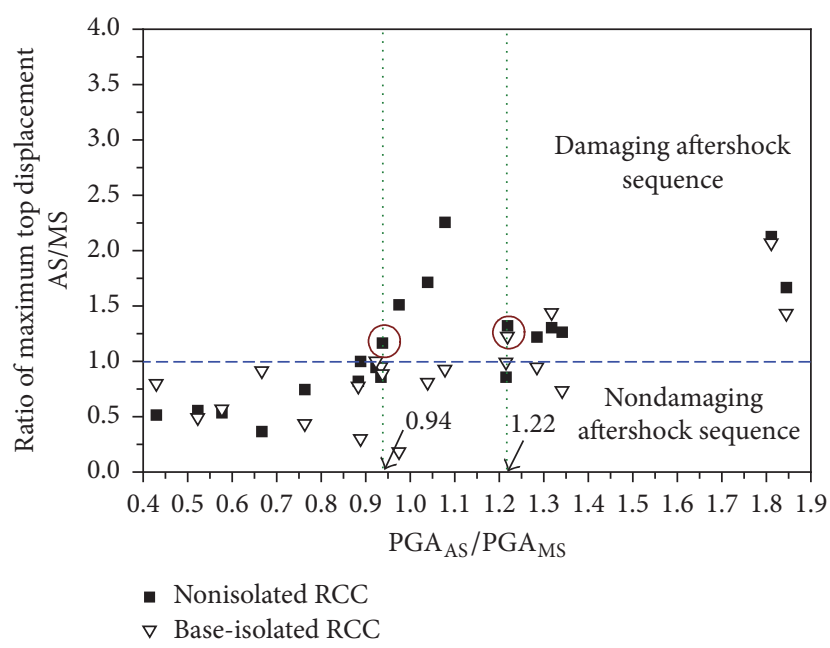

FIGURE 13: Ratio of maximum relative displacement as function of $\mathrm{PGA}_{\mathrm{AS}} / \mathrm{PGA}_{\mathrm{MS}}$.

for nondamaging sequences, the ratios are much lower in the medium- and long-period region (between the vibration period of $1.35 \mathrm{~s}$ and $6 \mathrm{~s}$ ), with the lowest values being equal to 1 around the isolation period. It is indicated that the spectral values of the aftershock around the isolation period are lower than those of the corresponding mainshock and therefore the responses controlled by the isolation mode during aftershocks may be lower than mainshocks. As a consequence, the damaging aftershock effect dominated by the structural mode can be more compromised as a result of lower responses contributed by the isolation mode during aftershocks, which further demonstrates the advantage of applying the isolation system to the RCC for seismic sequences.

4.3.2. Isolators. It should be noted that, for the baseisolated RCC, the decrease of relative displacements of the superstructure is at the expense of the increase of isolator displacements. Maximum displacements of isolators under mainshocks and seismic sequences appear in Table 5. From Table 5, the average maximum isolator displacement under mainshocks is $0.042 \mathrm{~m}$. By contrast, the value for seismic sequences increases to $0.057 \mathrm{~m}$, rising by $35.7 \%$ in comparison with mainshocks. It reveals that while the average $\mathrm{PGA}_{\mathrm{AS}} / \mathrm{PGA}_{\mathrm{MS}}$ has only 1.033 , indicating that the average intensity of the aftershocks is just that of the mainshocks, mainshock-aftershock effects must not be neglected for the design of isolators as larger deformations of isolators may increase the failure risk of pipelines between the isolated and fixed-base structures.

It is important to study the main characteristics of damaging aftershock sequences for the isolator displacement response. The ratio of the maximum isolator displacement for the mainshock-aftershock to that for the mainshock only is displayed in Figure 15 as function of $\mathrm{PGA}_{\mathrm{AS}} / \mathrm{PGA}_{\mathrm{MS}}$. In Figure 15, it can be found that greater isolator displacements due to aftershocks are caused by 9 of the 20 records for the 


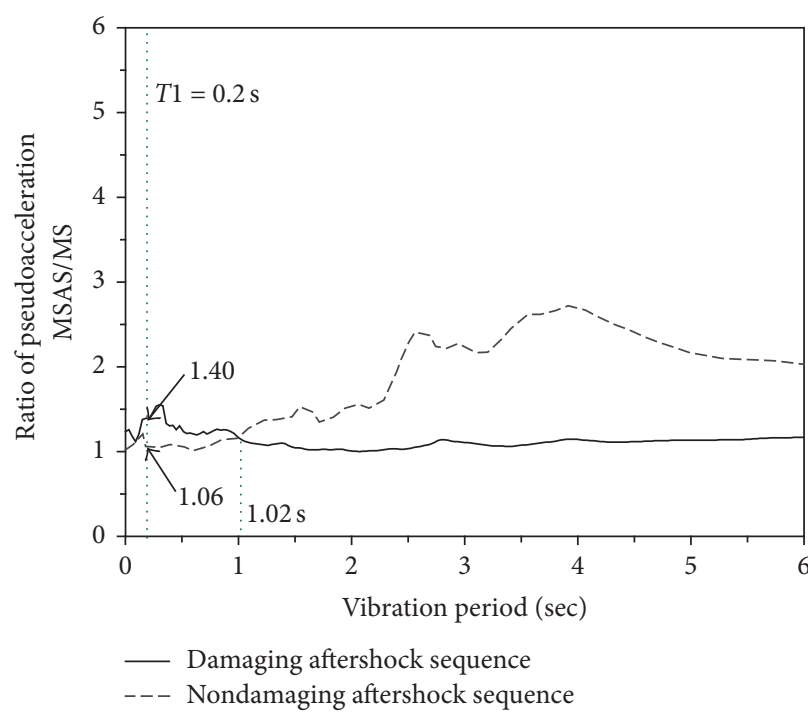

(a)

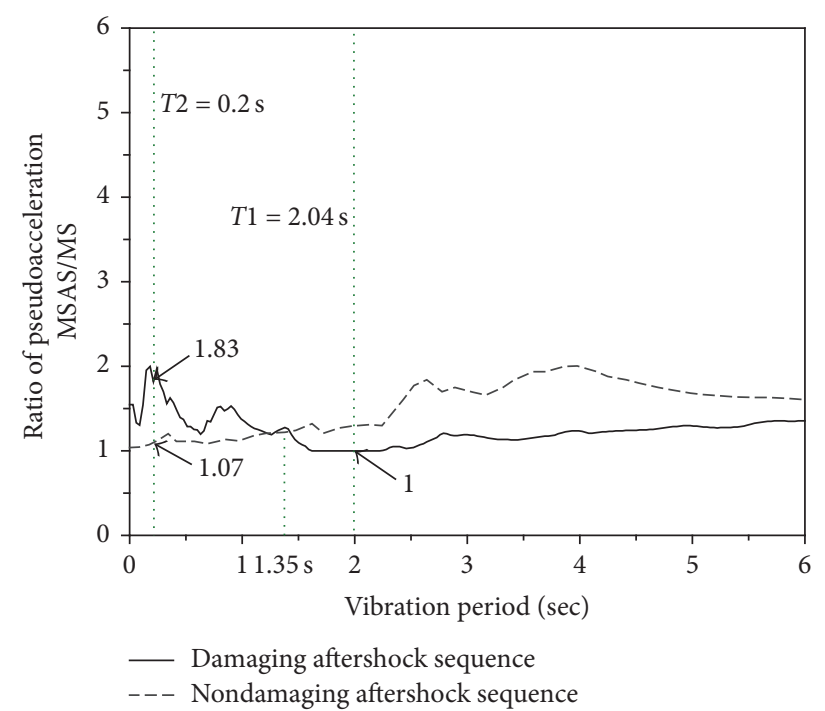

(b)

FIGURE 14: Ratio of response spectral statistics due to MSAS and MS record data for damaging and nondamaging sequences corresponding to relative displacement: (a) nonisolated RCC; (b) base-isolated RCC.

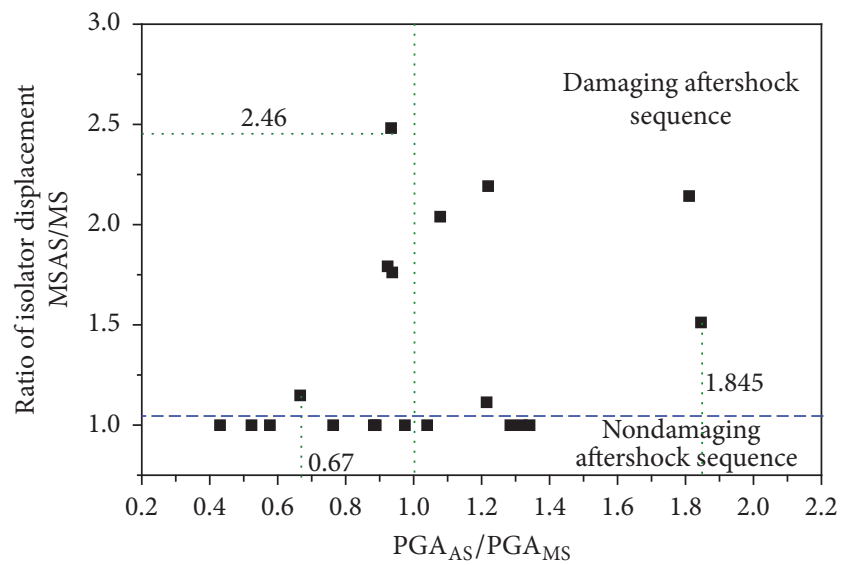

FIGURE 15: Ratio of maximum isolator displacement due to MSAS and MS record data as function of $\mathrm{PGA}_{\mathrm{AS}} / \mathrm{PGA}_{\mathrm{MS}}$.

$\mathrm{PGA}_{\mathrm{AS}} / \mathrm{PGA}_{\mathrm{MS}}$ value between 0.667 and 1.845 . The highest ratio of 2.46 occurs at the $\mathrm{PGA}_{\mathrm{AS}} / \mathrm{PGA}_{\mathrm{MS}}$ value equal to 0.934 . The increase of isolator displacements due to aftershocks is disproportionate to the relative intensity of aftershock ground motions $\left(\mathrm{PGA}_{\mathrm{AS}} / \mathrm{PGA}_{\mathrm{MS}}\right)$, which means that larger isolator displacements are associated with more factors such as different frequency and spectral shape between mainshocks and seismic sequences.

Figure 16 presents the ratio of the mean response spectra for the mainshock-aftershock to those for the mainshock. Clearly, the ratios for damaging aftershock sequences are greater than those for nondamaging sequences over the whole vibration period, particularly in the medium- and longperiod region (between $1 \mathrm{~s}$ and $6 \mathrm{~s}$ ). It indicates that the medium- and long-period structures, like the base-isolated

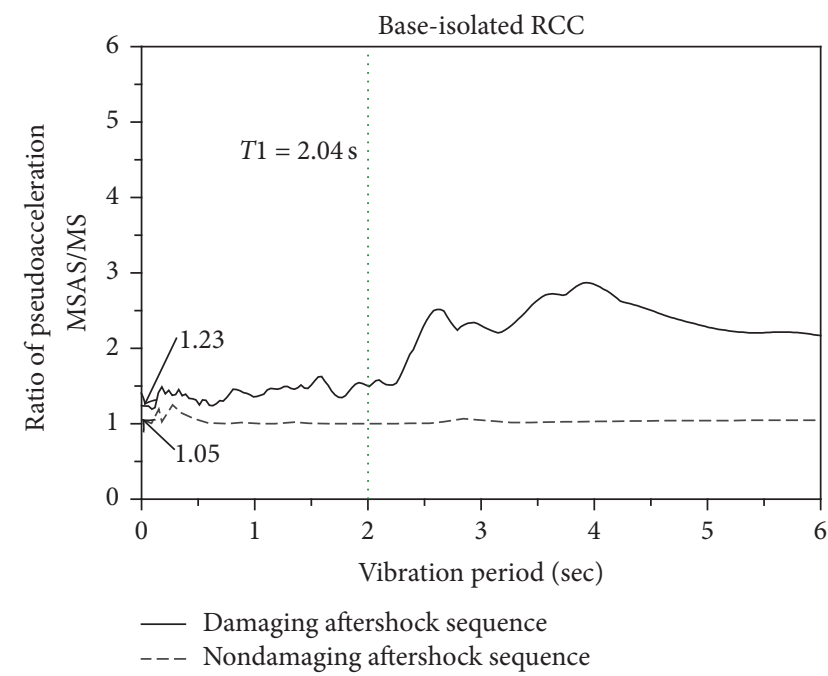

FIGURE 16: Ratio of response spectral statistics due to MSAS and MS record data for damaging and nondamaging sequences corresponding to isolator displacement.

RCC, may suffer greater additional global displacements (or isolator displacements) from the aftershocks with the larger spectral values in the medium- and long-period region in comparison with the mainshocks.

\section{Conclusions}

In this paper, in order to research the effect of sequential ground motions on the base-isolated RCC building, a suitable finite element model for the base-isolated RCC is set up. For comparison, a fixed-base RCC is also built. A contrast of the analysis results including acceleration and displacements 
indicates that base isolation technique is an effective and efficient way to reduce the seismic demand of the RCC subject to sequential ground motions. The summarized findings are as follows:

(a) Obtained acceleration results show that the average maximum top acceleration of the base-isolated RCC can reduce by $85.7 \%$ under mainshocks and $86.3 \%$ under sequential ground motions. It is indicated that base isolation system can be applied to the RCC to reduce the seismic shaking of the RCC and facilitate the standardization of facility designs for seismic sequences. The results also show that the damaging aftershock effect on acceleration responses of the RCC would be reduced if the base isolation is applied to the RCC.

(b) In comparison with the fixed-base RCC, average maximum top displacements for the base-isolated RCC reduce by $84.9 \%$ under mainshocks and $86.6 \%$ under seismic sequences. By setting up the isolation system, no difference for average maximum top displacements of the superstructure can be found between mainshocks and seismic sequences. The results reveal that isolators can not only reduce the structural deformation significantly under earthquake excitations but also prevent strong aftershocks from causing additional deformation to the structure. Additionally, base isolation can reduce the damaging aftershock effect on displacement responses of the RCC significantly.

(c) It is observed that the average maximum isolator displacement for seismic sequences rises by $35.7 \%$ in comparison with the mainshocks, which indicates that mainshock-aftershock effects must not be neglected for the design of isolators as larger deformations of isolators may increase the failure risk of pipelines between the isolated and fixed-base structures. The medium- and long-period structures, like the base-isolated RCC, may suffer greater additional global displacement (or isolator displacement) from the aftershocks with larger spectral values in the medium- and long-period region in comparison with the mainshocks.

(d) Ratio of response spectral statistics reveals that damaging aftershock sequences for both the fixed-base RCC and the superstructure of the RCC with isolators are more associated with greater aftershock response spectral values around the structural period $(0.2 \mathrm{~s})$ of the RCC. Notice that damaging aftershock sequences for the superstructure of the base-isolated RCC have no direct relevance with the aftershock spectral values around the isolation period (2.04 s).

\section{Conflicts of Interest}

The authors declare that they have no conflicts of interest.

\section{Acknowledgments}

This study received support from the China Scholarship Council.

\section{References}

[1] A. S. Elnashai and L. Di Sarno, Fundamentals of Earthquake Engineering, Wiley, Chichester, UK, 2008.

[2] C. Amadio, M. Fragiacomo, and S. Rajgelj, "The effects of repeated earthquake ground motions on the non-linear response of SDOF systems," Earthquake Engineering \& Structural Dynamics, vol. 32, no. 2, pp. 291-308, 2003.

[3] S. Das, V. K. Gupta, and V. Srimahavishnu, "Damage-based design with no repairs for multiple events and its sensitivity to seismicity model," Earthquake Engineering \& Structural Dynamics, vol. 36, no. 3, pp. 307-325, 2007.

[4] L. Di Sarno, "Effects of multiple earthquakes on inelastic structural response," Engineering Structures, vol. 56, pp. 673-681, 2013.

[5] K. Goda and C. A. Taylor, "Effects of aftershocks on peak ductility demand due to strong ground motion records from shallow crustal earthquakes," Earthquake Engineering \& Structural Dynamics, vol. 41, no. 15, pp. 2311-2330, 2012.

[6] K. Goda, "Nonlinear response potential of MainshockAftershock sequences from Japanese earthquakes," Bulletin of the Seismological Society of America, vol. 102, no. 5, pp. 2139-2156, 2012.

[7] G. D. Hatzigeorgiou and D. E. Beskos, "Inelastic displacement ratios for SDOF structures subjected to repeated earthquakes," Engineering Structures, vol. 31, no. 11, pp. 2744-2755, 2009.

[8] G. D. Hatzigeorgiou, "Behavior factors for nonlinear structures subjected to multiple near-fault earthquakes," Computers and Structures, vol. 88, no. 5-6, pp. 309-321, 2010.

[9] G. D. Hatzigeorgiou, "Ductility demand spectra for multiple near- and far-fault earthquakes," Soil Dynamics and Earthquake Engineering, vol. 30, no. 4, pp. 170-183, 2010.

[10] A. Moustafa and I. Takewaki, "Response of nonlinear singledegree-of-freedom structures to random acceleration sequences," Engineering Structures, vol. 33, no. 4, pp. 1251-1258, 2011.

[11] S. Efraimiadou, G. D. Hatzigeorgiou, and D. E. Beskos, "Structural pounding between adjacent buildings subjected to strong ground motions: Part II: the effect of multiple earthquakes," Earthquake Engineering and Structural Dynamics, vol. 42, no. 10, pp. 1509-1528, 2013.

[12] A. Faisal, T. A. Majid, and G. D. Hatzigeorgiou, "Investigation of story ductility demands of inelastic concrete frames subjected to repeated earthquakes," Soil Dynamics and Earthquake Engineering, vol. 44, pp. 42-53, 2013.

[13] M. Fakharifar, G. Chen, L. Sneed, and A. Dalvand, "Seismic performance of post-mainshock FRP/steel repaired RC bridge columns subjected to aftershocks," Composites Part B: Engineering, vol. 72, pp. 183-198, 2015.

[14] G. D. Hatzigeorgiou and A. A. Liolios, "Nonlinear behaviour of RC frames under repeated strong ground motions," Soil Dynamics and Earthquake Engineering, vol. 30, no. 10, pp. 10101025, 2010.

[15] R. Han, Y. Li, and J. van de Lindt, "Seismic risk of base isolated non-ductile reinforced concrete buildings considering uncertainties and mainshock-aftershock sequences," Structural Safety, vol. 50, pp. 39-56, 2014. 
[16] M. Raghunandan, A. B. Liel, and N. Luco, "Aftershock collapse vulnerability assessment of reinforced concrete frame structures," Earthquake Engineering \& Structural Dynamics, vol. 44, no. 3, pp. 419-439, 2015.

[17] J. Shin, J. Kim, and K. Lee, "Seismic assessment of damaged piloti-type RC building subjected to successive earthquakes," Earthquake Engineering and Structural Dynamics, vol. 43, no. 11, pp. 1603-1619, 2014.

[18] S. Tesfamariam, K. Goda, and G. Mondal, "Seismic vulnerability of reinforced concrete frame with unreinforced masonry infill due to main shock-aftershock earthquake sequences," Earthquake Spectra, vol. 31, no. 3, pp. 1427-1449, 2015.

[19] M. Fragiacomo, C. Amadio, and L. Macorini, "Seismic response of steel frames under repeated earthquake ground motions," Engineering Structures, vol. 26, no. 13, pp. 2021-2035, 2004.

[20] D. Loulelis, G. D. Hatzigeorgiou, and D. E. Beskos, "Moment resisting steel frames under repeated earthquakes," Earthquake and Structures, vol. 3, no. 3-4, pp. 231-248, 2012.

[21] Y. Li, R. Q. Song, and J. W. Lindt, "Collapse fragility of steel structures subjected to earthquake mainshock-aftershock sequences," Journal of Structural Engineering, vol. 140, no. 12, Article ID 04014095, pp. 1-10, 2014.

[22] J. Ruiz-García and J. C. Negrete-Manriquez, "Evaluation of drift demands in existing steel frames under as-recorded farfield and near-fault mainshock-aftershock seismic sequences," Engineering Structures, vol. 33, no. 2, pp. 621-634, 2011.

[23] K. Goda and M. R. Salami, "Inelastic seismic demand estimation of wood-frame houses subjected to mainshock-aftershock sequences," Bulletin of Earthquake Engineering, vol. 12, no. 2, pp. 855-874, 2014.

[24] N. Nazari, J. W. Van De Lindt, and Y. Li, "Effect of mainshockaftershock sequences on woodframe building damage fragilities," Journal of Performance of Constructed Facilities, vol. 29, no. 1, Article ID 04014036, pp. 1-10, 2015.

[25] Y.-J. Yin and Y. Li, "Loss estimation of light-frame wood construction subjected to mainshock-aftershock sequences," Journal of Performance of Constructed Facilities, vol. 25, no. 6, pp. 504-513, 2011.

[26] C.-H. Zhai, Z. Zheng, S. Li, and L.-L. Xie, "Seismic analyses of a RCC building under mainshock-aftershock seismic sequences," Soil Dynamics and Earthquake Engineering, vol. 74, pp. 46-55, 2015.

[27] A. Mandara and M. Ferraioli, "Base isolation for seismic retrofitting of a multiple building structure: design, construction, and assessment," Mathematical Problems in Engineering, vol. 1, pp. 1-24, 2017.

[28] D. Zhao and Y. Li, "Fuzzy control for seismic protection of semiactive base-isolated structures subjected to near-fault earthquakes," Mathematical Problems in Engineering, no. 1, pp. $1-17,2015$.

[29] S. E. Abdel Raheem, "Exploring seismic response of bridges with bidirectional coupled modelling of base isolation bearings system," Arabian Journal for Science and Engineering, vol. 39, no. 12, pp. 8669-8679, 2014.

[30] F.-G. Fan and G. Ahmadi, "Seismic responses of secondary systems in base-isolated structures," Engineering Structures, vol. 14, no. 1, pp. 35-48, 1992.

[31] R. Lo Frano and G. Forasassi, "Isolation systems influence in the seismic loading propagation analysis applied to an innovative near term reactor," Nuclear Engineering and Design, vol. 240, no. 10, pp. 3539-3549, 2010.
[32] R. Lo Frano and G. Forasassi, "Preliminary evaluation of seismic isolation effects in a Generation IV reactor," Energy, vol. 36, no. 4, pp. 2278-2284, 2011.

[33] I. Micheli, S. Cardini, A. Colaiuda, and P. Turroni, "Investigation upon the dynamic structural response of a nuclear plant on aseismic isolating devices," Nuclear Engineering and Design, vol. 228, no. 1-3, pp. 319-343, 2004.

[34] C. Zhao and J. Chen, "Numerical simulation and investigation of the base isolated NPPC building under three-directional seismic loading," Nuclear Engineering and Design, vol. 265, pp. 484-496, 2013.

[35] S. Fujita, K. Minagawa, and T. Kodaira, "Required properties of seismic isolation system for nuclear power plants," in Proceedings of the ASME 2010 Pressure Vessels and Piping Division/KPVP Conference, PVP2010, pp. 193-199, July 2010.

[36] Y.-N. Huang, A. S. Whittaker, M. C. Constantinou, and S. Malushte, "Seismic demands on secondary systems in baseisolated nuclear power plants," Earthquake Engineering \& Structural Dynamics, vol. 36, no. 12, pp. 1741-1761, 2007.

[37] Y.-N. Huang, A. S. Whittaker, and N. Luco, "Seismic performance assessment of base-isolated safety-related nuclear structures," Earthquake Engineering \& Structural Dynamics, vol. 39, no. 13, pp. 1421-1442, 2010.

[38] C.-H. Zhai, Z. Zheng, S. Li, and X. Pan, "Damage accumulation of a base-isolated RCC building under mainshock-aftershock seismic sequences," KSCE Journal of Civil Engineering, vol. 21, no. 1, pp. 1-14, 2017.

[39] ABAQUS, User's Manual 6.10, Dassault Systèmes Simulia, Providence, RI, USA, 2010.

[40] Pacific Earthquake Engineering Research Center (PEER), PEER Strong Motion Database, University of California, Berkeley, Calif, USA, 2000, https://ngawest2.berkeley.edu/.

[41] J. Lubliner, J. Oliver, S. Oller, and E. Oñate, "A plastic-damage model for concrete," International Journal of Solids and Structures, vol. 25, no. 3, pp. 299-326, 1989.

[42] J. Lee and G. L. Fenves, "Plastic-damage model for cyclic loading of concrete structures," Journal of Engineering Mechanics, vol. 124, no. 8, pp. 892-900, 1998.

[43] S. Nagarajaiah, A. M. Reinhorn, and M. C. Constantinou, "Nonlinear dynamic analysis of 3-D-base-isolated structures," Journal of Structural Engineering, vol. 117, no. 7, pp. 2035-2054, 1991.

[44] T. E. Kelly, Base Isolation of Structures: Design Guidelines, Holmes Consulting Group Ltd., Auckland, New Zealand's, 2001.

[45] USNRC, "Design response spectra for seismic design of nuclear power plants,” Regulatory Guide 1.60, December 1993. 


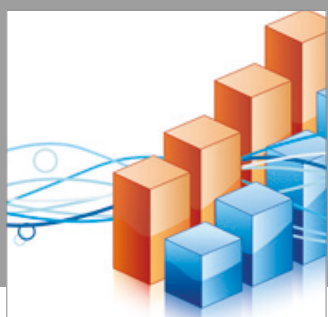

Advances in

Operations Research

vatersals

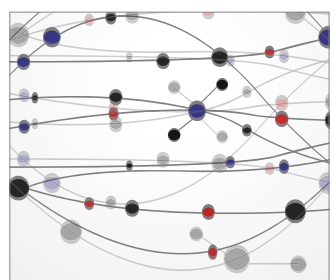

\section{The Scientific} World Journal
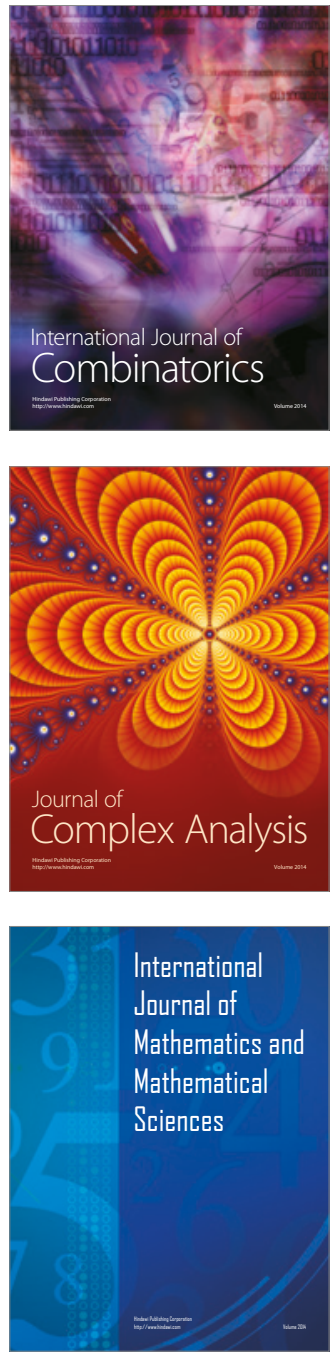
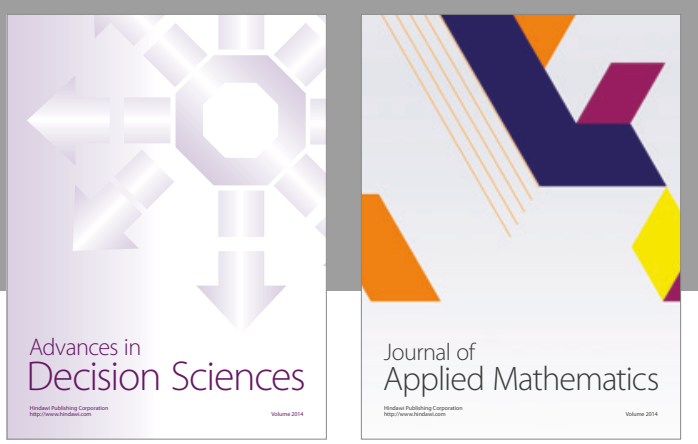

Algebra

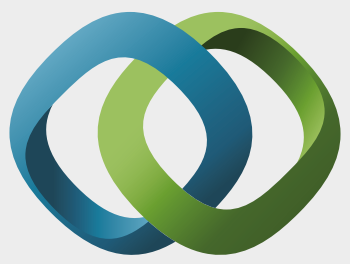

\section{Hindawi}

Submit your manuscripts at

https://www.hindawi.com
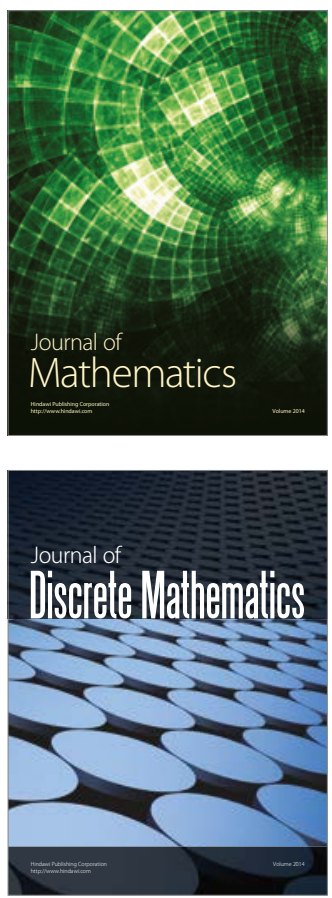

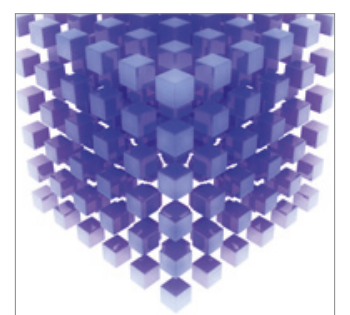

Mathematical Problems in Engineering
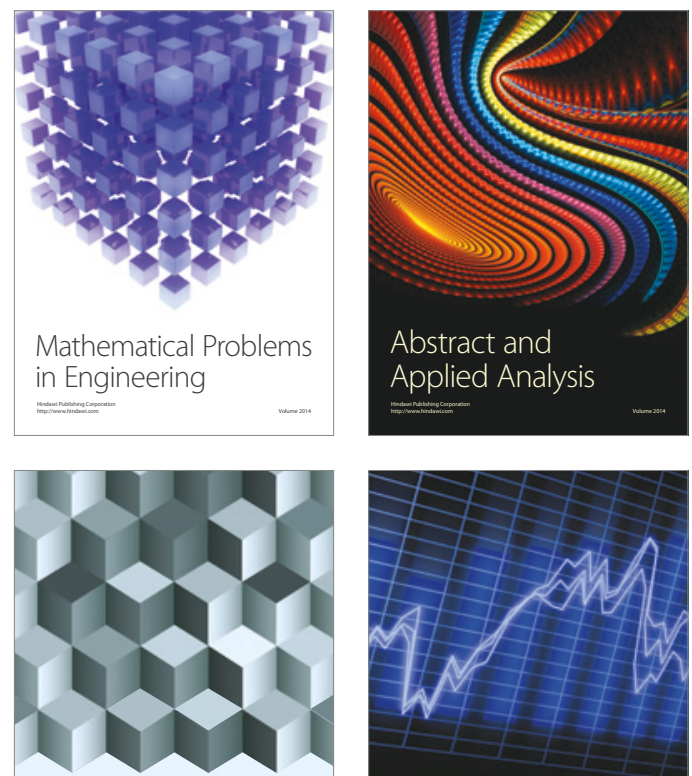

Journal of

Function Spaces

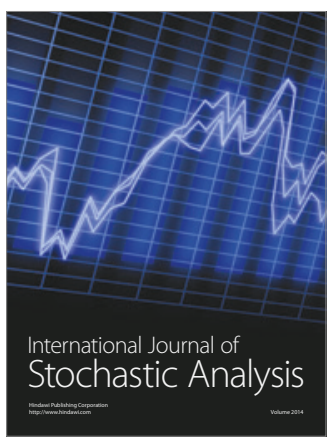

Probability and Statistics
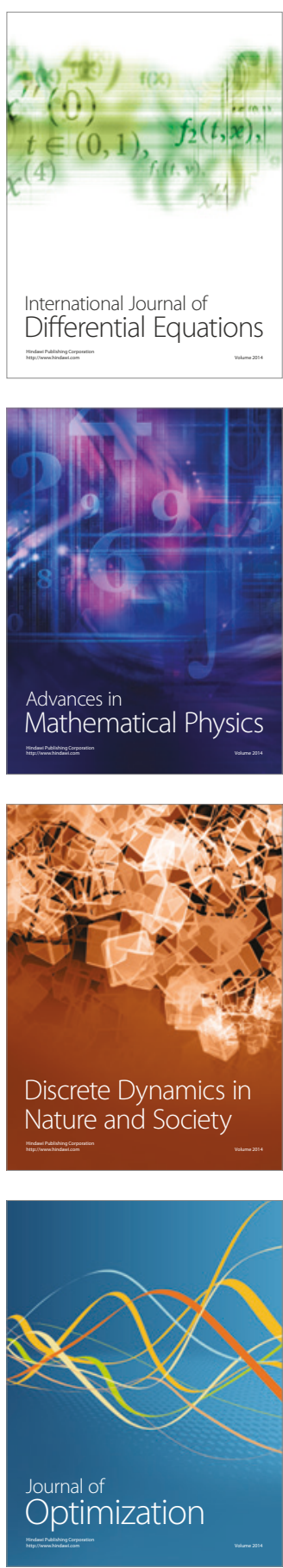